\title{
Vivências e percepções de familiares sobre a hospitalização da criança em unidade pediátrica
}

Experience and perception of family members on child's hospitalization in pediatric unit

Vivencias e impresiones de familiares sobre la hospitalización del niño en unidad pediátrica

\section{Tayane Próspero Cardoso ${ }^{\mathrm{I}}$, Pâmela Roberta de Oliveira ${ }^{\mathrm{II}}$, Rosa Jacinto Volpato ${ }^{\mathrm{III}}$ Vagner Ferreira do Nascimento ${ }^{\mathrm{IV}}$, Elias Marcelino da Rocha ${ }^{\mathrm{V}}$, Alisséia Guimarães Lemes ${ }^{\mathrm{VI}}$}

Resumo: Objetivo: identificar as percepções vivenciadas por familiares acompanhantes de crianças durante a hospitalização. Método: pesquisa exploratória, qualitativa, realizada em um setor pediátrico no interior de Mato Grosso, de maio a junho de 2015. Os dados foram obtidos por meio de entrevistas semiestruturadas com os familiares de crianças hospitalizadas e submetidos à análise temática. Resultados: as mães estavam mais presentes como acompanhantes durante a hospitalização e que, em alguns casos, aquele foi o primeiro contato com o setor de pediatria. A estrutura física foi considerada satisfatória. Alguns dos sentimentos e atitudes expressados foram desespero, medo, impotência/incapacidade, saudade e esperançaConsiderações finais: o estudo apontou a necessidade de acolhimento dos familiares durante a internação da criança por parte de toda a equipe de saúde,

\footnotetext{
${ }^{\text {I }}$ Enfermeira na Secretaria Municipal de Saúde de Barra do Garças-MT. Pós-Graduanda em Saúde Pública com ênfase em saúde mental pelo Centro Universitário do Vale do Araguaia (UNIVAR). Colaboradora no projeto de pesquisa em Saúde Mental da Universidade Federal de Mato Grosso (UFMT), Campus Universitário do Araguaia (CUA). Barra do Garças, Mato Grosso, Brasil. E-mail: tayanepc@gmail.com ORCID ID: https://orcid.org/0000-0003-2800-7573

II Enfermeira. Doutoranda no Programa de Pós-Graduação em Enfermagem pela Universidade Federal de Goiás (UFG). Professora Adjunta II no Curso de Enfermagem da Universidade Federal de Mato Grosso (UFMT), Campus Universitário do Araguaia (CUA). Colaboradora no projeto de pesquisa em Saúde Mental da UFMT/CUA. Barra do Garças, Mato Grosso, Brasil. E-mail: pamela_veira@yahoo.com.br ORCID ID: https://orcid.org/0000-0003-0497-6548

III Enfermeira. Mestra em Enfermagem pela Universidade Federal de São Carlos (UFSCar). Colaboradora no projeto de pesquisa em Saúde Mental da UFMT/CUA. Barra do Garças, Mato Grosso, Brasil. E-mail: rosamjacinto@hotmail.com ORCID ID: https://orcid.org/0000-0001-57097008

IV Enfermeiro. Doutor em Bioética pelo Centro Universitário São Camilo (CUSC). Professor Adjunto II no Departamento de Enfemagem da Universidade Estadual de Mato Grosso (UNEMAT), Campus Tangará da Serra. Colaborador no projeto de pesquisa em Saúde Mental da UFMT/CUA. Tangará da Serra, Mato Grosso, Brasil. E-mail: vagnerschon@hotmail.com. ORCID ID: https://orcid.org/0000-0002-3355-163X

$\checkmark$ Enfermeiro. Mestre em Ciências da Saúde pela Universidade de Brasília (UnB). Professor Assistente I no Curso de Enfermagem da Universidade Federal de Mato Grosso (UFMT), Campus Universitário do Araguaia (CUA). Colaborador no projeto de pesquisa em Saúde Mental da UFMT/CUA. Barra do Garças, Mato Grosso, Brasil. E-mail: elefamoso@hotmail.com ORCID ID: https://orcid.org/0000-0002-0086-8286

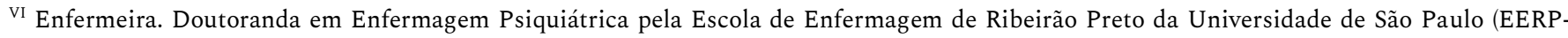
USP). Professora Assistente II no Curso de Enfermagem da Universidade Federal de Mato Grosso (UFMT), Campus Universitário do Araguaia (CUA). Coordenadora do projeto de pesquisa em Saúde Mental da UFMT/CUA. Barra do Garças, Mato Grosso, Brasil. E-mail: alisseia@hotmail.com ORCID ID: http://orcid.org/0000-0001-6155-6473
} 
Vivências e percepções de familiares sobre a hospitalização da criança em unidade pediátrica $\mid 2$

incluindo-os no processo de tratamento, atendendo suas necessidades físicas e psicológicas, contribuindo, desse modo, para a melhoria da assistência à criança.

Descritores: Convalescença; Criança hospitalizada; Enfermagem pediátrica; Família; Pediatria

\begin{abstract}
Aim: to identify the perceptions experienced by accompanying relatives of children during hospitalization. Method: exploratory, qualitative research carried out in a pediatric sector in the interior of Mato Grosso from May to June 2015. Data were obtained through semi-structured interviews with the relatives of hospitalized children and submitted to thematic analysis. Results: the mothers were more present as companions during the hospitalization and, in some cases, was the first contact with the pediatrics sector. The physical structure was considered satisfactory. Some of the feelings and expressed attitudes were despair, fear, impotence/ helplessness, longing, and hope. Final considerations: the study pointed out the need of reception of family members by the entire health team during the hospitalization of the child, including them in the treatment process, attending to their physical and psychological needs, thus contributing to the improvement of child care.
\end{abstract}

Descriptors: Convalescence; Child hospitalized; Pediatric nursing; Family; Pediatrics

Resumen: Objetivo: identificar las impresiones vividas por familiares acompañantes de niños durante la hospitalización. Método: investigación exploratoria, cualitativa, realizada en un sector pediátrico en el interior de Mato Grosso, de mayo a junio de 2015. Los datos fueron recolectados por medio de entrevistas semiestructuradas con los familiares de niños hospitalizados y sometidos al análisis temático. Resultados: las madres estaban más presentes como acompañantes durante la hospitalización y, en algunos casos, ese fue el primer contacto con el sector de pediatría. La estructura física fue considerada satisfactoria. Algunos de los sentimientos y actitudes expresados fueron desesperación, miedo, impotencia / incapacidad, nostalgia y esperanza. Consideraciones finales: el estudio destacó la necesidad de la acogida de los familiares durante la internación del niño por parte de todo el equipo de salud, incluyéndolos en el proceso de tratamiento, atendiendo sus necesidades físicas y psicológicas, contribuyendo así para la mejora de la asistencia al niño.

Descriptores: Convalecencia; Niño hospitalizado; Enfermería pediátrica; Familia; Pediatría

\title{
Introdução
}

A população pediátrica do hospital mudou ao longo das últimas décadas. Com a ascensão das cirurgias e dos cuidados ambulatoriais, uma grande porcentagem de crianças apresenta, atualmente, problemas mais graves e complexos do que as hospitalizadas no passado. Consequentemente, essas crianças estão sujeitas a um maior número de procedimentos invasivos e traumáticos enquanto permanecem internadas. ${ }^{1}$ Nesse sentido, torna-se imprescindível uma atenção especial voltada para as necessidades psicossociais e de desenvolvimento da criança, integrando a família no cuidado, uma vez que os efeitos da 
hospitalização podem afetar as duas partes, gerando nas crianças atitudes que visam ao afastamento inicial dos pais, assim como comportamentos negativos e de dependência. ${ }^{1}$

A presença do acompanhante durante a hospitalização é direito da criança estabelecido pela Lei 8.069, de 1990, o Estatuto da Criança e do Adolescente (ECA), e corrobora a evolução positiva de reações físicas e emocionais. ${ }^{2}$ Estudo demonstrou que o grupo de crianças com acompanhantes durante a hospitalização apresentou menor frequência de choro, vômitos, diarreia, taquicardia, inapetência, insônia, enurese noturna, assim como menor frequência de indiferença, medo, apatia, agressividade e irritabilidade, do que o grupo de crianças sem acompanhantes durante a internação. ${ }^{3}$

Embora a presença de algum membro da família seja imprecindivel no acompanhamento da criança durante sua internação, é necessário destacar que o familiar pode sofrer abalos emocionais durante esse processo. Isso leva a uma desorganização dos seus aspectos biopsicossociais, visto que a hospitalização altera tanto a vida da criança como a dinâmica da família, em especial, a vida da mãe que, na maioria dos casos, acompanha a criança durante toda a sua internação. ${ }^{4}$ Temas comuns são identificados como fatores estressores e causadores de reações entre os pais cujos filhos foram hospitalizados, a saber: sensação de desamparo; necessidade de receber informações explicativas em uma linguagem simples; e apoio para lidar com o medo, enfrentar a incerteza e restabelecer sua confiança com pensamentos positivos. ${ }^{1}$

Ressalta-se que esses fatores podem influenciar negativamente tanto a qualidade de vida desses familiares quanto a sua capacidade de oferecer acolhimento e de responder às demandas da criança em tratamento, o que pode prejudicar o enfrentamento da situação de internação. ${ }^{5}$

Ademais, durante a hospitalização, ocorre uma ruptura dos vínculos familiares, pois a família pode não saber exatamente como agir em um ambiente com regras estranhas para atender às necessidades do filho doente, o que aumenta o nível de ansiedade. ${ }^{6}$ Para minimizar os 
Vivências e percepções de familiares sobre a hospitalização da criança em unidade pediátrica... 4

efeitos estressores da hospitalização na admissão do paciente, deve ser realizada uma orientação sobre o que está ocorrendo com o doente e qual a sua necessidade de tratamento. ${ }^{7}$

Fornecer informações é uma das intervenções de enfermagem mais importantes e contribui para reduzir a ansiedade. ${ }^{1}$ A família precisa de explicações e orientações claras, em linguagem simples e compreensível, adequadas às suas crenças culturais e religiosas, que incluam orientações sobre as reações comportamentais normais dos filhos durante a hospitalização tais como: separação, regressão, agressão e hostilidade. Além disso, há necessidade de informações e esclarecimentos sobre as regras hospitalares. Portanto, é fundamental que os profissionais de saúde busquem novas estratégias de atuação e invistam no oferecimento de orientações e no esclarecimento das dúvidas dos familiares, com o objetivo de minimizar o sofrimento dessas pessoas. ${ }^{4}$

É importante reconhecer o papel essencial das redes de apoio às famílias durante a hospitalização e a importância da valorização de cada um desses elementos (família, equipe e espiritualidade) para o sucesso e a otimização do processo de enfrentamento familiar. ${ }^{8}$

Desse modo, a família deve ser vista como paciente/cliente secundário, pois o acompanhante se sente desconfiado e inseguro frente à realidade vivenciada durante a internação e carece de oportunidades para falar sobre a doença, sobre seus medos, sobre a morte e, sobretudo, para expressar suas emoções. ${ }^{7}$ Ouvir de forma acolhedora e humanizada os familiares que acompanham a criança internada maximiza os benefícios potenciais da hospitalização, além de ser um passo importante e fundamental para o planejamento da assistência de enfermagem centrada na família.

A justificativa deste estudo se sustenta em pesquisas ${ }^{3-5,7-8}$ que reforçam a importância essencial das redes de apoio às famílias durante a hospitalização da criança, atendendo às demandas, não apenas do paciente, mas também dos familiares, valorizando a compreensão da 
experiência subjetiva com efetivo acolhimento integral e humanizado da criança e de sua família. ${ }^{3-5,7-8}$

Com respaldo nas evidências científicas de que é dever do profissional enfermeiro atender às demandas biopsicossociais e espirituais da criança e da família provocadas pela doença e pela hospitalização, de modo a fortalecer o senso de competência e autonomia de ambos, ${ }^{1,6,9}$ é que se torna relevante o desenvolvimento de estudos como este para gerar melhoria na qualidade do atendimento prestado, com dignidade e respeito, à criança hospitalizada e à sua família.

Assim, a pergunta de pesquisa deste estudo foi: como os familiares que acompanham as crianças internadas na unidade pediátrica percebem e vivenciam a hospitalização? O delineamento do estudo ocorreu em consonância com o objetivo principal que foi: identificar as percepções vivenciadas por familiares acompanhantes de crianças durante a hospitalização.

\section{Método}

Trata-se de um estudo exploratório com abordagem qualitativa. A investigação foi realizada no setor de pediatria de um hospital público localizado no interior do estado de Mato Grosso, Brasil.

A unidade hospitalar onde este estudo foi realizado, atende $100 \%$ pelo Sistema Unico de Saúde (SUS) e é composta por seis setores, divididos em emergência/pronto socorro com 12 leitos, internação com 32 leitos, maternidade com 18 leitos, pediatria com 12 leitos, centro cirurgico com três salas e Unidade de Terapia Intensiva (UTI) adulto com seis leitos.

Foram convidados a participar do estudo todos os familiares que estavam acompanhando as crianças hospitalizadas no setor de pediatria no período de 01 maio a 30 junho de 2015. Obteve-se, após exclusão de 2 familiares, o total de 10 familiares que atendiam aos critérios de elegibilidade, a saber: ter idade igual ou superior a 18 anos; possuir vínculo familiar com a criança que estava hospitalizada no setor da pediatria; e ser o acompanhante da 
Vivências e percepções de familiares sobre a hospitalização da criança em unidade pediátrica... | 6

criança por um período superior a 24 horas após a admissão. Os critérios de exclusão foram: familiares acompanhantes de crianças indígenas que não se comunicavam em língua portuguesa, apenas em sua língua materna indígena o que dificultaria a comunicação entre pesquisadora e participante.

A coleta de dados foi realizada por meio de entrevistas semiestruturadas, compostas por perguntas que contemplaram aspectos sociodemográficos (sexo, grau de parentesco, faixa etária, escolaridade, estado civil, renda familiar e religião), assim como a percepção dos familiares relacionada ao ambiente hospitalar, suas expectativas sobre o prognóstico da criança e os sentimentos por eles vivenciados durante o período de hospitalização.

As entrevistas foram individuais, realizadas em ambiente calmo e silencioso na unidade pediátrica, gravadas em mídia eletrônica (voz) e com duração média de 40 minutos. Os dados foram transcritos na íntegra formando um banco de dados no Microsoft Word 2010 e armazenados com replicação em sistema de gravação em nuvem, a fim de garantir a segurança. Esses dados foram submetidos à análise de conteúdo, modalidade temática, por comportar um feixe de relações que pode ser graficamente apresentado por meio de uma frase cujo tema é a unidade de significação que se liberta naturalmente de um texto analisado. ${ }^{10}$

Primeiramente, as entrevistas foram submetidas a várias leituras com formulação e reformulação de hipóteses e objetivos, tendo como parâmetro a leitura exaustiva do material e as indagações iniciais. No segundo momento, foi realizada a exploração do material para alcançar o núcleo de compreensão do texto, ou seja, encontrar as categorias que se organizam em torno de expressões ou palavras significativas, em função das quais o conteúdo de uma fala é organizado.

Durante a análise dos dados, foram elencadas quatro categorias por meio dos critérios de repetição e relevância, sendo estas: percepção dos familiares relacionada ao ambiente hospitalar; sentimentos e expectativas dos familiares em relação ao prognóstico da criança; 
estratégias de enfrentamento das adversidades relacionadas à hospitalização da criança; e modificações nos papéis e nos hábitos de vida da família durante a hospitalização.

Atendendo à garantia do sigilo das identidades dos participantes, para a apresentação dos relatos, utilizou-se a letra "F" para familiares, seguida pelo número arábico correspondente à ordem na entrevista (F1 a F10).

A pesquisa atendeu às recomendações contidas na Resolução 466/2012 do Conselho Nacional de Saúde referente às diretrizes e normas regulamentadoras de pesquisa envolvendo seres humanos e foi aprovada, em 27 de janeiro de 2014, por meio do Parecer 515/705, pelo Comitê de Ética em Pesquisa da Universidade Federal de Mato Grosso/Campus Universitário do Araguaia.

\section{Resultados e discussão}

No Quadro 1, estão destacadas as características das crianças na época da entrevista. Nota-se que as crianças, em sua maioria, foram acompanhadas por suas genitoras, sendo internadas em decorrência de condições físicas e apresentaram uma média de internação de 5,1 dias.

\begin{tabular}{|l|c|c|c|c|}
\hline Descrição & $\begin{array}{c}\text { Idade da } \\
\text { criança na } \\
\text { internação }\end{array}$ & Motivo da internação & Dias de & Participante: familiar entrevistado \\
\hline Criança 1 & 3 anos & Fratura de fêmurãa & 05 dias & Código recebido \\
\hline Criança 2 & 13 dias & Hipóxia & 13 dias & Mãe (F1) \\
\hline Criança 3 & 7 anos & Amigdalite & 02 dias & Mãe (F3) \\
\hline Criança 4 & 5 anos & Gastroenterite Aguda & 03 dias & Mãe (F4) \\
\hline Criança 5 & 9 meses & Hidrocefalia & 07 dias & Mãe (F5) \\
\hline Criança 6 & 7 meses & Pneumonia & 02 dias & Mãe (F6) \\
\hline Criança 7 & 6 anos & Gastroenterite Aguda & 03 dias & Mãe (F8) \\
\hline Criança 8 & 6 dias & Sífilis Congênita & 06 dias & Mãe (F9) \\
\hline Criança 9 & 6 anos & Pneumonia & 05 dias & Mãa \\
\hline
\end{tabular}


Vivências e percepções de familiares sobre a hospitalização da criança em unidade pediátrica... $\mid 8$

\begin{tabular}{|l|l|l|l|l|}
\hline Criança 10 & 8 anos & Anemia Grave & 05 dias & Mãe (F10) \\
\hline
\end{tabular}

Quadro 1 - Características das crianças internadas no setor de pediatria de um hospiltal público no interior de Mato Groso, Brasil.

Com relação as características sociodemográficas dos familiares que acompanharam as crianças, destaca-se que as mulheres $(n=10)$ foram as responsáveis pelo acompanhamento da criança hospitalizada, com faixa etária de 23 a 39 anos, com grau de escolaridade variando entre superior completo, médio completo e médio incompleto (20\% respectivamente), casadas $(80 \%)$, com renda familiar entre um a dois salários mínimos (40\%) e $\geq 3$ salários mínimos (40\%), que se autodeclararam evangélicas $(60 \%)$ e católicas (20\%).

Rupturas dos vínculos e mudanças no padrão do papel familiar desempenhado pelos pais podem acontecer durante a hospitalização da criança. ${ }^{1,6}$ Estudo $^{11}$ apontou que ocorre uma (re)organização da família durante a hospitalização da criança, demonstrando que, à mulher, é atribuído o cuidado dos filhos, enquanto ao homem, muitas vezes por não apresentar a mesma facilidade no cuidar da criança que a mãe, atribui-se o papel de provedor do sustento da família. $^{12}$

Esse fato também foi verificado em uma revisão integrativa ${ }^{11}$ que identificou certa homogeneidade quanto à inclusão dos familiares que estavam acompanhando a criança durante a hospitalização, compondo amostras constituídas, majoritariamente, por mães.

Sobre a presença das mães acompanhando a criança durante o processo de hospitalização, a literatura aponta que quando elas permanecem junto aos seus filhos durante a internação, agem com o objetvo de minimizar o sofrimento da criança, preparando-a para passar pelos procedimentos de saúde, de forma que não lhe causem traumas. Para isso, elas trazem uma chupeta, ficam mais próximas, acalentam os filhos após a situação de estresse, impedem a realização de procedimentos, muitas vezes dolorosos e repetitivos, e insistem em 
comentar informações peculiares sobre a criança. Diante dessas atitudes, normalmente, as crianças choram menos, ficam mais calmas, melhoram mais rápido e se sentem protegidas. ${ }^{13}$

Por meio do relato das mulheres deste estudo, notou-se que as acompanhantes com maior grau de escolaridade demonstraram conhecer os direitos dos usuários do Sistema Único de Saúde para a internação da criança. Pesquisa sugere que o grau de escolaridade se correlaciona com o grau de potencialidade da família para acessar e compreender as informações e para obter novos conhecimentos. Nesse sentido, é importante a família "ter condições para entender os processos de doença e hospitalização pelos quais passam o seu ente querido, bem como para criar mecanismos de enfrentamento adequados”. 14:639 Cabe ressaltar que o baixo nível de escolaridade prejudica a compreensão das ações preventivas ou curativas voltadas à saúde. ${ }^{15}$

Finalmente, neste estudo, prevaleceram mulheres casadas, assim como também fora identificado em um estudo ${ }^{16}$ transversal realizado com familiares de crianças internas em um hospital universitário de Pelotas, Rio Grande do Sul (RS), predominando a renda mensal de um a dois salários mínimos. ${ }^{16}$

\section{Percepção dos familiares relacionada ao ambiente hospitalar}

As unidades hospitalares, principalmente em hospitais públicos, apresentam algumas particularidades que podem gerar (des)conforto. O desconhecimento do ambiente hospitalar pode ocasionar medo e ansiedade no acompanhante, ocasionando novas necessidades sociais, físicas e afetivas e, por mais simples que seja o motivo, a hospitalização tende a levar a uma experiência negativa. ${ }^{11}$ No que diz respeito ao conhecimento prévio de uma unidade pediátrica, metade das acompanhantes relatou ser a primeira experiência no setor de pediatria. Quanto à estrutura física do setor de pediatria, surgiram divergências entre as experiências relatadas. Para a maioria das acompanhantes, a estrutura física oferecida foi avaliada de forma positiva, com ênfase para o acolhimento e a atenção, os quais atendiam, segundo sua percepção, às necessidades das crianças; contudo, também houve avalições negativas. 
Vivências e percepções de familiares sobre a hospitalização da criança em unidade pediátrica... | 10

A estrutura física não está muito boa não. Está deixando muito a desejar, como todo hospital público, que atende pelo SUS. (F1)

Aqui é sombra e água fresca, ventilador dia e noite, durmo e como! O quê que eu tenho pra reclamar? Nada [...]. (F2)

Eu gostei daqui, gostei [...] Aqui está bom, foi bem atendido. Ele estava bem ruim, depois que ele chegou, tomou o remédio, ficou bem mais calmo. (F6)

Bom, eu tinha uma impressão diferente. Quando eu cheguei, eu fiquei assustada, porque eu fiquei lá embaixo [observação do setor de emergência] e é muita gente, muito movimento, muito pequeno o espaço, aí então eu pensei: Será que é aqui a pediatria? Aí ficou dois dias, depois que foi encaminhado para cá, [...] para pediatria, quando eu cheguei, que olhei o ambiente, eu falei: Nossa! Completamente diferente, gostei muito, fui muito bem tratada, gostando muito mesmo, a atenção é nota dez [...]. (F9)

Estudo $^{17}$ realizado em um hospital universitário em Natal, Rio Grande do Norte (RN) com setenta acompanhantes de crianças internadas revelou que 45,7\% relataram relativa demora no atendimento durante a internação da criança. No entanto, houve satisfação no que diz respeito ao repasse de informações sobre o paciente $(88,6 \%)$, ao tempo de visita $(75,7 \%)$ e à limpeza dos ambientes (75,7\%). Além disso, 65,7\% não sabiam onde fazer reclamações ou sugestões e 44,3\% desconheciam o nome dos profissionais que atendiam diretamente sua criança. ${ }^{17}$

Ainda sobre o impacto da estrutura física, pesquisa ${ }^{4}$ realizada em Goiás, descreveu que a acentuação do cansaço foi relacionada à falta de uma estrutura física adequada para o repouso dos acompanhantes, visto que as mães precisam estar continuamente alertas a qualquer alteração na condição clínica da criança, além de atender às suas demandas específicas de cuidado. 
Sobre esse aspecto, um estudo apontou que deve ser oferecida à família uma estrutura favorável ao contato diário com seu ente querido e com a equipe de saúde, humanizando a hospitalização com a participação da família no cuidado à criança e diminuindo as mudanças no seu cotidiano. ${ }^{18}$ Destaca-se também que um ambiente adequado, humanizado e acolhedor contribui para o alívio da dor e do sofrimento infantil com todos os recursos tecnológicos, psicológicos e lúdicos disponíveis durante o tempo de seu atendimento. ${ }^{13}$

\section{Sentimentos e expectativas dos familiares em relação ao prognóstico da criança}

Entre os sentimentos manifestados pelos familiares relacionados ao prognóstico da criança, o medo foi o mais citado pelas acompanhantes (80\%).

Eu fiquei com medo, porque ele estava na incubadora quatro dias. Eu nunca passei por essas experiências. Ele ficava na incubadora e eu ficava com medo de tirar ele de lá e ele ficar sem oxigênio e eu chegar a perder ele. (F2)

O medo pode ser observado na narrativa da acompanhante, causado por falta de compreensão do diagnóstico, pelo ambiente desconhecido, pela necessidade de procedimentos invasivos, pela probabilidade de piora na evolução clínica ou mesmo pela possibilidade de morte da criança.

Tais sentimentos também foram semelhantes entre familiares de crianças internas em uma Unidade de Terapia Intensiva (UTI) pediátrica, ${ }^{19}$ e entre familiares de crianças com doenças crônicas internadas no setor de pediatria no Sul do Brasil. ${ }^{20}$

Percebe-se que, quando uma criança é internada, vários fatores atingem os familiares, provocando desespero. Eles descrevem a circunstância como um momento muito difícil, horrível e aterrorizante, capaz de gerar um estado de preocupação intermitente.

É um desespero muito grande. Eu fiquei desesperada quando vi minha filha nessa situação, quando você pega o resultado do Raio X e o médico fala pra você que a 
Vivências e percepções de familiares sobre a hospitalização da criança em unidade pediátrica... | 12

perna da sua filha está fraturada, que o osso separou, que o mesmo osso separou em duas partes. (F1)

Um outro estudo explica que as alterações apresentadas na dinâmica das famílias que acompanham seus parentes em situação de hospitalização decorrem das necessidades internas, do equilíbrio emocional e das pressões externas (quebra da rotina de trabalho e dificuldades financeiras). Tudo isso interfere no autocuidado e na qualidade de vida e podem ainda gerar sentimentos de depressão, angústia, raiva, tristeza, medo, culpa e frustração. ${ }^{21}$

Outro sentimento também verificado neste estudo foi a confiança, apontada por metade das acompanhantes. A confiança é representada pela segurança no tratamento e pelo uso de diferentes tecnologias de saúde que auxiliam na recuperação das crianças. As mães se mostram confiantes, sobretudo por acreditarem que tudo isso é essencial para a melhora da saúde da criança enferma. Contudo, essa confiança vem seguida de uma certa ansiedade, gerada pelo processo de hospitalização.

[...] Tive muita informação assim em relação ao tratamento recebido, a equipe que cuida dele [...] É o que dá mais confiança, pois, por mais que o problema do meu filho fosse grave, eles conseguiam passar pra mim uma segurança. (F10)

Os sentimentos de confiança, esperança e força também foram verificados entre familiares de crianças que frequentam uma instituição de reabilitação em São José dos Campos São Paulo (SP). ${ }^{22}$ Esses sentimentos tornaram-se preditores, que buscam amenizar a dor e o sofrimento de familiares, contribuindo ainda para a sua confiança em relação à melhora do prognóstico clínico da criança enferma. ${ }^{19}$

\section{Estratégias de enfrentamento das adversidades relacionados à hospitalização da criança}

Em busca de estratégias que permitam a superação de obstáculos durante a hospitalização, o papel das fontes de apoio assume condição primordial. Nesse sentido, um 
estudo apontou três principais segmentos como fontes de apoio acionadas por mães no processo de enfrentamento da internação neonatal: a equipe de saúde, a família e a espiritualidade. ${ }^{8}$

As mulheres participantes desta pesquisa declararam acreditar e confiar em Deus. A crença religiosa e a espiritualidade têm ajudado os familiares a encontrar paz e conforto diante da angústia e da ansiedade que permeiam a hospitalização, contribuindo para a superação do sofrimento.

Eu acho que é uma luta, mas, assim com a força de Deus, é a única força que eu tenho pra estar rompendo e achando que vai acontecer sempre o melhor. É só por crer em Deus, porque do jeito que ele ficou [...]. (F4)

É uma fase que vai passar. Eu creio em Deus e o Deus que eu sigo não é um Deus morto e eu sei que Ele vai ajudar ela a passar por essa prova. (F7)

Quando uma pessoa fica enferma, a família se organiza e utiliza estratégias diferenciadas para lidar com o sofrimento, dentre elas destaca-se a espiritualidade. Nessa perspectiva, estar ligado a uma religião parece representar uma estrutura de apoio às pessoas no que diz respeito ao enfrentamento de seus problemas diários, contribuindo para uma maior satisfação com a vida e para a ausência de sentimentos de desamparo e desesperança. ${ }^{23}$

Estudo $^{5}$ apontou que há diferenças significativas entre os participantes não praticantes de uma religião e os praticantes no que diz respeito a um maior uso da estratégia de enfrentamento “aceitação de responsabilidade”, a qual se refere à atitude de se culpar frente à situação de adoecimento da criança.

Assim, a crença e a espiritualidade dão sentido à vida e aos acontecimentos presentes nela, diminuindo os conflitos e o sentimento de culpa que surgem diante de uma situação inesperada e de sofrimento. ${ }^{5}$

Observou-se que as acompanhantes, em sua maioria, se autodeclararam religiosas e faziam uso de sua fé em Deus como possibilidade de refúgio, focando em pensamentos positivos que as confortaram e mantiveram confiantes na melhora clínica de suas crianças. 
Vivências e percepções de familiares sobre a hospitalização da criança em unidade pediátrica... | 14

Nada, só fé em Deus. (F3)

[Choro] [...] Só Deus e, olhando para ele, só de olhar para ele eu sei que vai dar tudo certo, já deu tudo certo, só de eu estar vendo que ele está vivo, que ele está bem, está ótimo. (F8)

Oro né! Eu oro todos os dias, coloco na presença de Deus. Os meus irmãos da igreja estavam vindo, orando também. (F9)

Fé em Deus. Eu não tenho religião, mas eu acredito num Deus vivo, um Deus que cura, um Deus que pode todas as coisas. Então, independente de religião, eu tenho meu Deus, eu sei que Ele escuta minhas orações e eu sei que Ele já curou ele. (F10)

estudo $^{5}$ realizado com familiares de crianças com leucemia em tratamento no interior de SP apontou resultados semelhantes ao desta pesquisa, pois a maioria dos participantes destacou a espiritualidade como sendo uma ferramenta crucial para auxiliá-los no enfrentamento dos problemas. Dessa forma, percebe-se que os cuidadores têm na espiritualidade um alívio para o sofrimento ocasionado pelo adoecimento de suas crianças e, nela, buscam forças para enfrentar a situação e continuar cuidando..$^{5,11}$

\section{Modificações nos papéis e nos hábitos de vida da família durante a hospitalização}

Esta pesquisa evidenciou que houve modificações na rotina dos familiares para se adaptar ao processo de hospitalização da criança. Essas mudanças na rotina da família também foram apontadas em outros estudos, pois a presença de um familiar em tempo integral no ambiente hospitalar desorganiza e dificulta o gerenciamento dos afazeres diários, no lar ou no trabalho. ${ }^{4,11,19,21}$

Do dia que ele nasceu, estou aqui mais ele. Larguei tudo para trás e vim para cá, treze dias aqui e vou muito mais se for preciso. (F2) 
O meu tempo agora é só para ele, não estou trabalhando e ficar o tempo todo com ele, o importante é a saúde dele. (F4)

As narrativas confirmam que houve uma desorganização temporária na rotina da família, de modo semelhente ao que foi constatado em outros estudos, ${ }^{4,19-20}$ os quais reforçam que, após a hospitalização de um membro da família, passa a existir um empenho focado exclusivamente na melhora clínica da criança, passando a contar com outras pessoas da família ou de sua confiança para reorganizar suas tarefas diárias e assim facilitar a adaptação à nova rotina. ${ }^{4,19-20}$

No caso das mães, essa situação atinge seu relacionamento familiar, sua saúde física e mental e a manutenção de sua rede social.

[Choro] [...] Meu marido ficou com meu outro filho, nunca fiquei longe assim, sabe, do meu outro filho, do meu emprego, da minha família. (F6)

[...] Não vejo mais meus familaires, estou sempre nervosa com tudo [...]. (F10)

Além disso, a falta de apoio dos outros membros da família agrava o sofrimento e realça o isolamento social a que são submetidas essas mães.,11 Nesse sentido, um sentimento mencionado pelos familiares, relacionado à alteração do papel familiar, foi a saudade dos demais membros da família, seja por não residirem na mesma cidade, seja por não poderem frequentar o ambiente hospitalar.

Não consigo me manter calma. Tenho muita dó dele e do outro, que ficou lá em casa, difícil! O outro tem três anos e quatro meses, esse tem sete meses [Choro].

[...] não vejo mais meu marido, praticamente não vou mais em casa, vivo aqui no hospital. Mesmo quando eu saio, algum telefone toca, você já pensa no pior e só saio daqui quando ele sair. (F10)

Dessa forma, a preocupação relacionada à nova rotina estabelecida acaba desorientando os familiares, os quais acabam se encontrando envoltos em dúvidas pelo desconhecimento do 
Vivências e percepções de familiares sobre a hospitalização da criança em unidade pediátrica... | 16

que está acontecendo com os outros membros da família. Essa situação desperta sentimentos de saudade, de tristeza e, ao mesmo tempo, de tensão.

Dados semelhantes foram encontrados nos relatos de outras mães/acompanhantes que vivenciaram, além da preocupação com os outros filhos que ficaram em casa, o cansaço, o desgaste emocional, a falta de tempo para o cuidado de si mesma, a tristeza, a angústia e até mesmo a culpa pela doença da criança. ${ }^{4,23}$ Assim, o desgaste emocional e a falta de estar junto do seu parente compromentem a necessidade de descanso durante a noite, pois a vida fora do hospital fica em suspensão. ${ }^{21}$

Os acompanhantes estão mais propensos a adoecer do que os outros familiares e amigos, pois a permanência no ambiente hospitalar, a negação do cuidado de si e o contato direto com a pessoa dependente de cuidados mobilizam as tensões interiores e acarretam sofrimento psíquico. ${ }^{11}$

Ainda nesse contexto, é relevante considerar que a criança, quando necessita de internação, também sofre mudanças em sua rotina, pois tende a conviver com limitações orgânicas e psicológicas, em um ambiente estranho. A necessidade de afastamento do seu domicílio e a exposição a múltiplos procedimentos técnicos faz da internação um tempo de significativos conflitos emocionais. ${ }^{18}$

Dessa forma, o processo de hospitalização de uma criança se traduz como experiência difícil e agitada, envolvendo a criança e sua família, que vivenciam significativas modificações na rotina diária e nas inter-relações entre os seus membros. ${ }^{18}$

É necessário entender que cada família desenvolve uma maneira única de enfrentar a hospitalização, não havendo espaço para padronizações ou generalizações. Daí a necessidade e a importância de buscar estratégias para melhor conhecer a família e entender seus comportamentos e sentimentos, pois isso possibilita a promoção de cuidados extensivos a ela e não somente à criança doente. ${ }^{11}$ 
Assim, é importante que os profissionais de saúde reconheçam o familiar no processo de recuperação e sua importância para o bem-estar da criança, oferecendo um suporte mais humanizado, capaz de apoiá-los e de inseri-los no plano terapêutico da criança hospitalizada.

\section{Considerações finais}

Neste estudo, observou-se que as mães estão mais presentes como acompanhantes durante a hospitalização e que, em alguns casos, aquele foi o primeiro contato com o setor de pediatria.

$\mathrm{Na}$ percepção da maioria dos familiares, a estrutura física foi considerada satisfatória. Isso é importante visto que torna-se necessário que a estrutura seja planejada e bem organizada para poder tornar o ambiente o mais tranquilo e acolhedor possível para a criança e seu acompanhante passarem pelos momentos de profundo estresse físico e emocional gerado no período de internação.

Observou-se uma nuance de sentimentos e atitudes dos familiares frente à hospitalização da criança. Os sentimentos negativos foram traduzidos em desespero, medo e impotência/incapacidade. Dado esperado, pois havia um familiar adoecido em uma situação de delicada vulnerabilidade. Ao mesmo tempo, os familiares expressaram sentimentos e atitudes positivas como a fé, a confiança e a esperança, demonstrando força diante das adversidades e convicção na melhoria clínica da criança, mesmo encontrando-se, momentaneamente, em um local que lhe causa estranheza e medo. Além disso, declararam que se sentiam seguros quanto aos cuidados recebidos pela criança hospitalizada.

O estudo também revelou uma alteração na rotina das crianças e de seus familiares durante o processo de internação, o que foi capaz de provocar nos acompanhantes sentimentos negativos (saudade, tristeza e tensão), que podem influenciar na recuperação da criança enferma. Assim, os resultados apontam para a necessidade do acolhimento global e humanizado dos familiares durante o processo de internação da criança, com a participação de diferentes 
Vivências e percepções de familiares sobre a hospitalização da criança em unidade pediátrica... | 18

membros da equipe multidisciplinar de saúde no trabalho de inclui-los no processo terapêutico de tratamento, atendendo às suas necessidades biopsicossociais e espirituais, potencializando assim, os benefícios da hospitalização e da sistematização da assistência de enfermagem à criança e sua família.

Por fim, como limitação do estudo, considera-se o fato de este retratar uma realidade regional, de modo que não deve ser generalizado. Portanto, faz-se necessária a realização de novos estudos desta natureza em outras realidades de unidades pediátricas, em âmbito nacional e internacional.

Pode-se afirmar que as discussões sobre esta temática são indispensáveis para a produção de conhecimento sobre a atuação da enfermagem nos cuidados à criança hospitalizada e sua família, de modo a fornecer subsídios para o desenvolvimento de um modelo de atenção que contemple, com respeito e dignidade, as subjetividades e as individualidades do amplo expectro de vivências e respostas humanas advindas do processo de hospitalização.

Como implicações para a prática, a partir da realização deste estudo, tem-se a possibilidade de favorecer a promoção de uma relação de cuidado atenciosa, acolhedora e humanizada, voltada à criança hospitalizada e seus familiares acompanhantes, e que facilite e promova a cura, a saúde e a qualidade de vida.

\section{Referências}

1. Sanders J. Cuidado centrado na família da criança durante a doença e a hospitalização. In: Hockenberry MJ, Wilson D. Wong, Fundamentos da enfermagem pediátrica. Rio de Janeiro: Elsevier; 2011. p. 675-702.

2. Centro de Defesa dos Direitos da Criança e do Adolescente (CEDECA). ECA 2017 Estatuto da Criança e do Adolescente [cartilha]. Rio de Janeiro: CEDECA; 2017. p. 24-78.

3. Oliveira GF, Dantas FDC, Fonsêca PN. O impacto da hospitalização em crianças de 1 a 5 anos de idade. Rev SBPH [Internet]. 2004 [acesso em 2018 jan 13];7(2):37-54. Disponível em: http://pepsic.bvsalud.org/pdf/rsbph/v7n2/v7n2a05.pdf. 
4. Santos LF, Oliveira LMAC, Barbosa MA, Siqueira KM, Peixoto MKAV. Reflexos da hospitalização da criança na vida do familiar acompanhante. Rev Bras Enferm [Internet]. 2013 [acesso em 2018 mar 16];66(4):473-78. Disponível em: http://www.scielo.br/scielo.php?script=sci_arttext\&pid=S0034-71672013000400002\&lng=pt. 5. Faria AMDB, Cardoso CL. Aspectos psicossociais de acompanhantes cuidadores de crianças com câncer: stress e enfrentamento. Estud Psicol (Campinas, Online) [Internet]. 2010 [acesso em 2018 jan 17];27(1):13-20. Disponível em: http://www.scielo.br/pdf/estpsi/v27n1/v27n1a02.

6. Sabatés AL. Reações da criança ou do adolescente e de sua família relacionadas à doença e à hospitalização. In: Almeida FA, Sabatés AL. Enfermagem pediátrica: a criança, o adolescente e sua família no hospital. Barueri: Manole; 2008. p. 49-56.

7. Ferreira PD, Mendes TN. Família em UTI: importância do suporte psicológico diante da iminência de morte. Rev SBPH [Internet]. 2013 [acesso em 2017 out 13];16(1):88-112. Disponível em: http://pepsic.bvsalud.org/pdf/rsbph/v16n1/v16n1a06.pdf.

8. Oliveira K, Veronez M, Higarashi IH, Corrêa DAM. Vivências de familiares no processo de nascimento e internação de seus filhos em UTI neonatal. Esc Anna Nery Rev Enferm [Internet]. 2013 [acesso em 2018 mar 16];17(1):46-53. Disponível em: http://www.redalyc.org/pdf/1277/127728366007.pdf.

9. Bowden VR, Grennberg CS. Princípios do cuidado centrado na família. In: Bowden VR, Grennberg CS. Procedimentos de enfermagem pediátrica. Rio de Janeiro: Guanabara Koogan; 2017. p. 3-5.

10. Bardin L. Análise de conteúdo. São Paulo: Edições 70; 2011.

11. Albuquerque DB, Morais RCM, Macedo IF, Vieira RFC, Souza TV. A família no cenário hospitalar pediátrico a partir da década de 1990: uma revisão integrativa. Cogitare Enferm [Internet]. 2013 [acesso em 2018 mar 16];18(4):789-95. Disponível em: http://www.redalyc.org/articulo.oa?id=483649282024.

12. Nascimento VF, Maciel MM, Lemes AG, Borges AP, Terças ACP, Hattori TY. Percepções de familiares sobre hospitalização no ambiente intensivo. Rev Enferm UFPI [Internet]. 2015 [acesso em 2018 fev 08];4(2):92-9. Disponível em: http://www.ojs.ufpi.br/index.php/reufpi/article/view/3402/pdf.

13. Gomes GC, Leite FLLM, Souza NZ, Xavier DM, Cunha JC, Pasini D. Estratégias utilizadas pela família para cuidar a criança no hospital. Rev Eletrônica Enferm [Internet]. 2014 [acesso em 2017 fev 05];16(2):434-42. Disponível em: https://www.fen.ufg.br/revista/v16/n2/pdf/v16n2a21.pdf. 
14. Maruiti MR, Galdeano LE, Farah OGD. Ansiedade e depressão em familiares de pacientes internados em unidade de cuidados intensivos. Acta Paul Enferm [Internet]. 2008 [acesso em 2018 jan 05];21(4):636-42. Disponível em: http:/www.scielo.br/pdf/ape/v21n4/a16v21n4.pdf.

15. Freitas KS, Kimura M, Ferreira KASL. Necessidades de familiares de pacientes em unidades de terapia intensiva: análise comparativa entre hospital público e privado. Rev Latinoam Enferm [Internet]. 2007 [acesso em 2018 jan 05];15(1):1-9. Disponível em: http://www.scielo.br/pdf/rlae/v15n1/pt_v15n1a13.pdf.

16. Granzotto JA, Mota DM, Vecchi AA, Santos EO, Gonçalves ER, Silva JBY, et al. Características sociodemográficas maternas e perfil das crianças internadas em um hospital do Sul do Brasil. Rev Enferm UFSM [Internet]. 2014 [acesso em 2018 jan 13];4(1):97-104. Disponível em: https://periodicos.ufsm.br/reufsm/article/view/8466/pdf.

17. Medeiros YKF, Mororó DDS, Pinto JTJM, Rocha NSPD, Fonseca GS. Quality of care provided to the hospitalized child from the perspective of the companion. Rev Rene [Internet]. 2017 [acesso em 2018 mar 17];18(4):499-506. Disponível em: http://periodicos.ufc.br/rene/article/view/20236/30794.

18. Nascimento VF, Maciel MM, Terças ACP, Lemes AG, Hattori TY, Demarchi RF, et al. Apreensões e sentimento de fé de familiares no ambiente de cuidado intensivo. Rev Gest Saúde [Internet]. 2015 [acesso em 2018 fev 03];6(3):2639-55. Disponível em: http://periodicos.unb.br/index.php/rgs/article/view/22406.

19. Pêgo CO, Barros MMA. Unidade de terapia intensiva pediátrica: expectativas e sentimentos dos pais da criança gravemente enferma. Rev Bras Ciênc Saúde [Internet]. 2017 [acesso em 2018 fev 03];21(1):11-20. Disponível em: http://periodicos.ufpb.br/ojs/index.php/rbcs/article/view/23827/16430.

20. Gomes GC, Mota MS, Moreira MAJ, Jung BC, Xavier DM, Silva CD. (Des)preparation of family member for the care of children with chronic illness. Rev Enferm UFPI [Internet]. 2017 [acesso em 2018 jan 08];6(1):47-53. Disponível em: http://www.ojs.ufpi.br/index.php/reufpi/article/view/5737/pdf. 21. Passos SSS, Pereira Á, Nitschke RG. Cotidiano do familiar acompanhante durante a hospitalização de um membro da família. Acta Paul Enferm [Internet]. 2015 [acesso em 2018 mar17];28(6):539-45. Disponível em: http://www.scielo.br/scielo.php?script=sci_arttext\&pid=S0103-21002015000600539\&lng=en.

22. Silva CCB, Ramos LZ. Reações dos familiares frente à descoberta da deficiência dos filhos. Cad Ter Ocup UFSCar [Internet]. 2014 [acesso em 2017 dez 09];22(1):15-23. Disponível em: http://www.cadernosdeterapiaocupacional.ufscar.br/index.php/cadernos/article/view/537/483. 
23. Medrado EDD, Whitaker MCO. Experiências de familiares durante a hospitalização de sua criança/adolescente em uma unidade pediátrica. Rev Soc Bras Enferm Ped [Internet]. 2012 [acesso em 2018 jan 13];12(2):123-30. Disponível em: https://sobep.org.br/revista/images/stories/pdf-revista/vol12-n2/Art_4_Experiencias_Evelin.pdf.

\section{Contribuições de Autoria:}

\section{1 - Tayane Próspero Cardoso}

Concepção e projeto, análise e interpretação dos dados; redação do artigo e revisão crítica relevante do conteúdo intelectual; e aprovação final da versão a ser publicada.

\section{2 - Pâmela Roberta de Oliveira}

Análise e interpretação dos dados; redação do artigo e revisão crítica relevante do conteúdo intelectual.

\section{3 - Rosa Jacinto Volpato}

Análise, interpretação dos dados e redação do artigo.

\section{4 - Vagner Ferreira do Nascimento}

Análise, interpretação dos dados, redação do artigo e revisão crítica relevante do conteúdo intelectual.

\section{5 - Elias Marcelino da Rocha}

Análise, interpretação dos dados e redação do artigo.

\section{6 - Alisséia Guimarães Lemes}

Concepção e projeto; análise e interpretação dos dados; redação do artigo e revisão crítica relevante do conteúdo intelectual; e aprovação final da versão a ser publicada.

\section{Como citar este artigo}

Cardoso TP, Oliveira PR, Volpato RJ, Nascimento VF, Rocha EM, Lemes AG. Vivências e percepções de familiares sobre a hospitalização da criança em unidade pediátrica. Rev. Enferm. UFSM. 2019 [Acesso em: 2019 jun 15];vol ex:1-22. DOI:https://doi.org/10.5902/2179769231304 